\title{
The Serotonin Reuptake Inhibitor Paroxetin Is Superior to the Noradrenaline Reuptake Inhibitor Maprotiline in the Treatment of Premenstrual Syndrome
}

Elias Eriksson, M.D., Marina A. Hedberg, M.D., Björn Andersch, M.D., and Charlotta Sundblad, M.D.

Recent studies indicate that antidepressant drugs with potent serotonin reuptake inhibiting properties are effective in reducing the symptoms of premenstrual syndrome (PMS). In order to elucidate whether all antidepressant drugs are equally effective in the treatment of PMS or whether potent serotonin reuptake inhibition is a prerequisite for reducing premenstrual complaints, women suffering from severe PMS were treated daily for three menstrual cycles with a selective serotonin reuptake inhibitor, paroxetine $(\mathrm{n}=22)$, or with a selective noradrenaline reuptake inhibitor, maprotiline $(\mathrm{n}=21)$; in addition, a placebo group was included $(\mathrm{n}=22)$. Six symptoms (irritability, depressed mood, tension/anxiety, increased appetite/craving for carbohydrates, bloating, and breast tenderness) were rated by the participants daily throughout the study. With respect to all outcome measurements, the symptom reduction obtained with paroxetine was significantly superior to that obtained with placebo; with respect to irritability, increased appetite/carbohydrate craving, bloating, and breast tenderness, as well as global self-rating, paroxetine was significantly superior also to maprotiline. The clear-cut superiority of paroxetine over maprotiline indicates that not all antidepressant drugs are equally effective in the treatment of PMS; rather, like panic disorder and obsessive compulsive disorder, but in contrast to depression, PMS apparently responds better to serotonin reuptake inhibitors than to antidepressants with a noradrenergic profile. [Neuropsychopharmacology 12:167-176, 1995]
KEY WORDS: Premenstrual syndrome; Late luteal phase dysphoric disorder; Irritability; Antidepressants; Paroxetin; Serotonin reuptake inhibitor; Maprotiline; Noradrenaline reuptake inhibitor

From the Department of Pharmacology (EE, CS) and the Department of Obstetrics and Gynaecology (BA), University of Göteborg, Sweden; Department of Psychiatry (MAH), Kungälv Hospital, Kungälv, Sweden.

Address correspondence to: Elias Eriksson, Department of Pharmacology, University of Göteborg, Medicinaregatan 7, S-413 90 Göteborg, Sweden.

Received May 25, 1994; revised October 4, 1994; accepted October 10, 1994 .
Premenstrual syndrome (PMS) (or late luteal phase dysphoric disorder, LLPDD) is characterized by a cluster of psychiatric and somatic symptoms regularly appearing around ovulation or during the 2 weeks preceding the menstrual bleeding and terminating within a few days after the onset of menstruation (American Psychiatric Association 1985; Frank 1931; Halbreich et al. 1982; Merikangas et al. 1993). The cardinal symptoms of PMS are irritability and depressed mood; in addition, tension, anxiety, increased carbohydrate craving, bloating, and breast tenderness are common complaints. A majority of all women experience mild premenstrual complaints; whereas most of these women are capable of mastering their symptoms without medi- 
cation, several independent studies indicate that as much as $10 \%$ of all menstruating women have premenstrual complaints of such severity that they would like to medicate in order to reduce them (Andersch et al. 1986; Chihal 1987; Reid 1985; see also Merikangas et al. 1993).

Clomipramine is an antidepressant drug that inhibits the reuptake inactivation of transmittor in both serotonin and noradrenaline synapses in brain. In an open study (Eriksson et al. 1989, 1990), followed by two confurmative placebo-controlled trials (Sundblad et al. $1992,1993)$, we have shown that low doses of clomipramine markedly reduce the symptoms of PMS with a response rate close to $100 \%$. Given the alleged involvement of serotonin in symptoms such as irritability and craving for carbohydrates (Eriksson and Humble 1990), we hypothesized that the impressive effect of clomipramine in reducing premenstrual complaints was specifically related to the potent serotonin reuptake inhibiting effect of the drug. According to this hypothesis, antidepressant drugs acting via other mechanisms, such as selective noradrenaline reuptake inhibitors, would not be expected to reduce premenstrual complaints as effectively as does clomipramine. Alternatively, given the facts that depressed mood is one of the cardinal symptoms of PMS and that there is a marked comorbidity of premenstrual syndrome and depression (Graze et al. 1990; Pearlstein et al. 1990), it might be suggested that PMS is in fact a form of atypical depression (Hallman 1986). If this is the case, one might expect all antidepressant drugs to be equally effective in reducing premenstrual complaints, regardless of whether they preferentially influence the serotonin or the noradrenaline synapse.

Supporting the importance of serotonin reuptake inhibition in the treatment of premenstrual complaints, several recent trials have shown that the selective serotonin reuptake inhibitor fluoxetine is effective in reducing the symptoms of PMS (Menkes et al. 1992; Rickels et al. 1990; Stone et al. 1991; Wood et al. 1992); on the other hand, another selective serotonin reuptake inhibitor, fluvoxamine, was reported ineffective (Veeninga et al. 1990). In support of the concept that strong serotonin reuptake inhibition is not a prerequisite for obtaining a beneficial effect of an antidepressant in PMS, a preferential (albeit not selective) noradrenaline reuptake inhibitor, nortriptyline, has been reported to be effective (Harrison et al. 1989).

Given the large number of women suffering from PMS to such an extent that they would like to medicate in order to reduce their complaints, the issue of whether all antidepressants are equally effective in reducing premenstrual complaints is of considerable clinical importance. Moreover, a clarification of the relative efficacy of serotonin and noradrenaline reuptake inhibitors, respectively, in reducing the various symptoms of PMS may provide further insight into the role of the two transmittors for various aspects of human behavior.
In the present study three groups of women with severe PMS/LLPDD received medication daily for three consecutive menstrual cycles; the first group was treated with a selective serotonin reuptake inhibitor, paroxetine (Caley and Weber 1993; Turner et al. 1989); the second group was treated with a selective noradrenaline reuptake inhibitor, maprotiline (Pinder et al. 1977), whereas the third group received a placebo.

\section{METHODS}

\section{Recruitment of Participants}

Women with severe premenstrual irritability and/or depressed mood were recruited by means of a newspaper advertisement followed by a brief telephone interview and a subsequent, extensive, structured interview. The primary inclusion criteria were marked irritability and/or depressed mood starting regularly around ovulation or during the 2 weeks preceding the menstrual bleeding and terminating within a few days after the onset of menstruation, as reported by the patient during the interview. In addition, the criteria of LLPDD in DSM-III-R should be fulfilled. Exclusion criteria were: (1) previous or ongoing psychiatric illness (apart from major depressive disorder or dysthymic disorder); (2) ongoing major depressive disorder or dysthymic disorder (as defined using DSM-III-R and by means of the Montgomery-Åsberg Depression Scale); (3) major depressive disorder or dysthymic disorder less than 2 years from the time of the interview; (4) ongoing medication for somatic or psychiatric illness with the exception of casual analgetics; (5) ongoing medication with oral contraceptives; (6) ongoing alcohol abuse; (7) ongoing diagnosed somatic illness as reported by the patient during interview; (8) irregular menstruations; (9) ongoing or planned pregnancy; (10) patients under 18 years of age; and (11) previous treatment with antidepressants for premenstrual complaints. Informed consent was obtained from all participants.

Before starting medication, all participants performed daily rating with respect to the possible occurrence of (1) irritability, (2) depressed mood, (3) tension/anxiety, (4) increased appetite and/or carbohydrate craving, (5) bloating, and (6) breast tenderness, respectively, for two subsequent menstrual cycles using a visual analogue scale (VAS) $(0-100 \mathrm{~mm} ; 0 \mathrm{~mm}=$ no complaints, $100 \mathrm{~mm}=$ maximum complaints). Subjects not displaying the following evidence of menstrually related changes during both reference cycles were excluded from the study: (1) an increase of over $100 \%$ in either irritability or depressed mood (or both) during the premenstrual phase (calculated as the mean rating of the 5 days preceding the first day of menstruation) as compared to the postmenstrual phase (calculated as the mean rating of days 6 to 10 of the cycle; cycle day $1=$ the first day of menstruation). (2) Mean premenstrual 
rating of irritability or depressed mood exceeding 20 $\mathrm{mm}$. In addition, some participants were excluded during the course of the two reference cycles because of other reasons (such as pregnancy and onset of depression).

\section{Medication}

After the 2 months of symptom rating, patients not excluded were randomized to one of the three treatment groups. Capsules containing placebo, maprotiline, or paroxetine were identical in shape, size, and color, and both patients and investigators were unaware of whether the patient was given placebo or one of the two active substances until the study was completed. Treatment started at the first day of menstruation; during the first week, the dose was one tablet daily containing $10 \mathrm{mg}$ of paroxetine or $25 \mathrm{mg}$ of maprotiline or placebo. During the second week of treatment, the patients took two tablets daily, containing either $10+0$ $(=10)$ mg paroxetine or $25+25(=50)$ mg maprotiline or placebo. After another 7 days of treatment the doses were increased to three tablets daily, containing $10+$ $10+0(=20) \mathrm{mg}$ paroxetine or $25+25+25(=75)$ $\mathrm{mg}$ maprotiline or placebo. During the fourth treatment cycle, and for the rest of the trial, the recommended dose was two tablets daily, containing $10+10 \mathrm{mg}$ $(=20) \mathrm{mg}$ paroxetine or $50+50(=100) \mathrm{mg}$ maprotiline or placebo. However, patients experiencing marked side effects of the treatment were instructed to decrease the dose to one tablet daily $(10 \mathrm{mg}$ paroxetine or $50 \mathrm{mg}$ maprotiline); on the other hand, patients experiencing no or mild side effects and an unsatisfactory reduction of premenstrual complaints during the course of the first premenstrual phase were allowed to increase the dosage from two to three tablets daily $(10+10+10$ $=30 \mathrm{mg}$ paroxetine or $50+50+50=150 \mathrm{mg}$ maprotiline). After the onset of the menstruation in the third treatment cycle, the patients were instructed to gradually taper the medication.

\section{Serum Drug Concentrations}

For determination of serum levels of paroxetine and maprotiline, blood samples were obtained in the morning 1 to five days before the menstrual bleeding during treatment cycle 3 ; the preceding intake of medication should have occurred 8 P.M. the evening before. Serum levels of paroxetine and maprotiline were measured using high-pressure liquid chromatography (Dr. Finn Bengtsson, Department of Clinical Pharmacology, University of Lund).

\section{Effect Assessment}

During the three treatment cycles, the participants performed daily symptom ratings using the same 1 to 100 mm VAS as during the two pretreatment reference cycles (see earlier). In order to obtain a global assessment of possible drug effects, after the last treatment cycle all patients were asked to estimate how they felt with respect to their premenstrual complaints during treatment as compared to how they felt before (enormously improved $=+3$, much improved $=+2$, somewhat improved $=+1$, no change $=0$, somewhat deteriorated $=-1$, much deteriorated $=-2$, enormously deteriorated $=-3$ ).

\section{Tolerability Assessment}

Before the start of the trial, the participants were informed of the various side effects that could be expected from treatment with paroxetine and maprotiline, respectively. For reporting the appearance of unwanted effects of the treatment, as well as the duration of the symptom in question, the participants completed a questionnaire comprising 19 possible side effects at the end of each treatment cycle; in addition, they were asked to indicate any additional symptom not appearing in the list that they attributed to the treatment.

\section{Analysis of Data}

For statistical analysis of differences between the three treatment groups, the mean rating during the 5 days preceding the menstrual bleeding in each treatment cycle was used as a measure of premenstrual symptomatology, whereas the mean rating of cycle day 6 to 10 was used as a measure of postmenstrual complaints.

For assessment of the relative symptom reduction, the difference between the baseline rating (i.e., the mean rating of the two reference cycles) and the rating of the third treatment cycle was calculated and expressed as percent reduction of baseline rating. Premenstrual syndrome is a heterogenous syndrome, thus, some patients were completely devoid of one or several of the rated symptoms already during the reference cycles. Since the calculation of the relative change (expressed as percents) of a rating close to zero may be misleading, percent improvement for a given symptom was not calculated for patients displaying a baseline rating under $5 \mathrm{~mm}$ for that particular symptom. Since symptom rating obtained with VAS cannot be expected to be normally distributed, nonparametric statistics were used for all statistical analyses. Thus, for comparisons of the three treatment groups with respect to relative improvement (as \% of baseline rating), pre- and postmenstrual rating for each cycle (as absolute numbers), and global improvement, the Kruskal-Wallis test, followed by the Mann-Whitney U-test, were used. In line with the protocol for the trial, only patients completing the study were included in the effect assessment. $p$-Values under .05 were regarded as statistically significant. 


\section{RESULTS}

\section{Number of Dropouts and Fulfillers}

Of 171 women recruited by means of a telephone interview and a subsequent structured interview (see Methods), 34 women for varying reasons chose not to participate in the study. Another 56 subjects were excluded from the study for one or both of the following reasons: (1) They were found to fulfil one or more of the exclusion criteria during the two pretreatment reference cycles (see Methods). (2) They were found not to display a menstrually related cyclical pattern with respect to irritability and/or depressed mood (as defined in Methods) during the reference cycles.

Eighty-one subjects hence started medication with paroxetine $(n=27)$, maprotiline $(n=28)$, or placebo $(n=26)$. Five paroxetine-treated patients dropped out during the trial, three because of side effects, one because of pregnancy, and one because of irregular menstruations. In the maprotiline group, seven patients dropped out during the trial; all seven withdrew from treatment because of side effects. In the placebo group, four subjects dropped out during the trial; two of these attributed side effects of the treatment as the reason for withdrawing, one dropped out because of the onset of other illness, and one was excluded since she repeatedly forgot to take her tablets. Thus, 65 patients fulfilled the trial protocol ( 22 on paroxetine, 21 on maprotiline, and 22 on placebo). Since most dropouts occurred before the completion of the premenstrual phase of the first treatment cycle, an intention-to-treat analysis comprising both dropouts and fulfillers could not be undertaken. One placebo-treated patient completed the three cycles of medication but failed to submit the daily symptom rating protocol for the last treatment cycle and was thus included in the analysis of the global rating only. Mean age ( \pm SEM) of the patients in the paroxetine group was $38 \pm 1$ years, in the maprotiline group $38 \pm 1$ years, and $37 \pm 1$ years in the placebo group.

One of the patients in the paroxetine group, two of the patients in the maprotiline group, and two of the patients in the placebo group reported that they had previously been treated for depression. No other patient reported any previous episodes of affective illness.

\section{Medication}

After the dose titration undertaken during the furst and, to some extent, second treatment cycles, in the placebo group 15 subjects had chosen a plateau dose of 3 tablets daily whereas the remaining 7 subjects took 2 tablets as maximal dose. In the paroxetine group the plateau dose was $30 \mathrm{mg} /$ day for 4 subjects, $20 \mathrm{mg} /$ day for 14 subjects, and $10 \mathrm{mg} /$ day for 4 subjects. In the maprotiline group, the plateau dose was $150 \mathrm{mg} /$ day for $10 \mathrm{sub}$ jects, $100 \mathrm{mg} /$ day for 9 subjects, and $50 \mathrm{mg} /$ day for 2 subjects.

\section{Serum Concentrations of Paroxetine and Maprotiline}

For practical reasons, blood samples for determination of serum concentrations of paroxetine or maprotiline could not be obtained from all participants; thus, serum drug analyses were undertaken in 14 patients from the placebo group, 12 patients from the maprotiline group, and 13 patients from the paroxetine group. Maprotiline was detected in all samples obtained from subjects in the maprotiline group, with concentrations ranging from 34 to $548 \mathrm{nmol} / \mathrm{L}$ (median: $195 \mathrm{nmol} / \mathrm{L}$ ). In one subject from the paroxetine group, taking 10 $\mathrm{mg} /$ day, no drug was detectable in serum (detection limit: appr. $3 \mathrm{nmol} / \mathrm{L}$ ); as judged by the side effects reported by this patient (sexual dysfunction, headache) and by her marked clinical response, noncompliance is not a likely explanation to this observation. In the rest of the patients in the paroxetine-treated group, serum paroxetine concentrations ranged from 4 to 139 $\mathrm{nmol} / \mathrm{L}$ (median: $28 \mathrm{nmol} / \mathrm{L}$ ). Neither in the maprotiline group nor in the paroxetine group did serum concentrations of active compound correlate significantly to clinical improvement or to the number of tablets taken (data not shown).

\section{Effect Assessment}

The reduction in each of the six rated symptoms observed during the last treatment cycle, expressed as percent of baseline rating ( $=$ the mean rating of the two pretreatment reference cycles), is shown in Figure 1. For all six items, the symptom reduction was significantly larger in the paroxetine group than in the placebo group; in contrast, the maprotiline group and the placebo group never differed significantly. For the four symptoms irritability, increased appetite/carbohydrate craving, bloating, and breast tenderness, the symptom reduction obtained with paroxetine was significantly greater than that obtained with maprotiline, whereas for the two symptoms depressed mood and anxiety/tension, the two groups given active treatment did not differ significantly.

The premenstrual symptom rating (absolute numbers) for all six symptoms during the two pretreatment reference cycles and the three treatment cycles are shown in Table 1. No significant differences between the groups were observed before treatment; however, with respect to depressed mood, the ratings of the maprotiline group tended to be lower than the ratings of the other two groups. During treatment, the symptom rating of the paroxetine group was significantly lower than that of the placebo group for all symptoms, with the exception of increased appetite/carbohydrate craving, for at least two of the three treatment cycles. With respect to premenstrual irritability, a sense of bloating, and breast tenderness, the rating of the parox- 


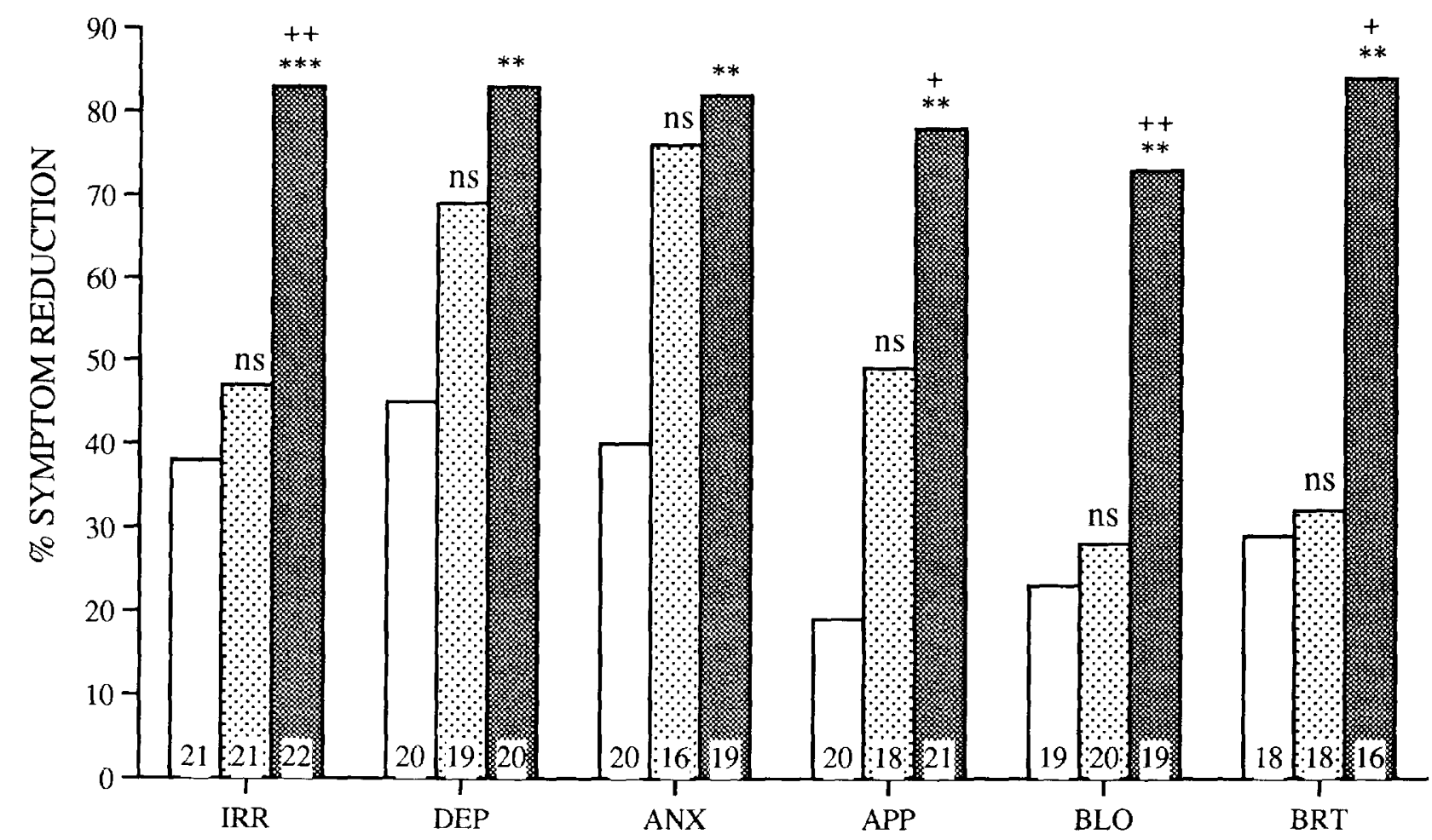

Figure 1. Percent reduction in premenstrual irritability (IRR), depressed mood (DEP), anxiety (ANX), increased appetite (APP), sense of bloating (BLO), and breast tenderness (BRT) in patients treated with placebo (open bars), maprotiline (dotted bars), or paroxetine (filled bars). Bars represent medians. Within each bar is indicated the number of subjects displaying the symptom in question before treatment and hence included in the calculation (see Methods). Levels of significance: ${ }^{\star \star} p<$ .01 versus placebo; ${ }^{* * *} p<.001$ versus placebo; $+p<.05$ versus maprotiline; $++p<.01$ versus maprotiline; ns $=$ not significant versus placebo.

etine group was significantly lower also than that of the maprotiline group for at least two of the treatment cycles. The rating of the maprotiline group was lower than that of the placebo group with respect to depressed mood and anxiety/tension but not with respect to the other four symptoms. For all symptoms rated, median postmenstrual ratings were low $(<9)$ in all treatment groups both before and during treatment (data not shown).

As shown in Table 2, global change in PMS symptomatology during treatment, as assessed by the patients, was significantly more favorable in the paroxetine group than in the groups given placebo or maprotiline. The maprotiline and placebo groups did not differ significantly.

\section{Tolerability Data}

All symptoms reported as possible side effects of the treatment by the patients completing the trial are shown in Table 3. Statistical analysis of the occurrence of side effects lasting for more than 10 days per treatment cycle by means of a Chi-square test revealed a significant difference between the three groups for the following unwanted effects: dry mouth (cycle 1: $p<.001$; cycle 2: $p<.001$; cycle 3: $p<.001$ ); gastritis (cycle 2: $p<.05$ ); obstipation (cycle 1: $p<.001$; cycle 2: $p<.001$; cycle $3: p<.01$ ); yawnings (cycle 1: $p<.05$; cycle $2: p<.05$ ), and sexual side effects (cycle 3: $p<.05$ ). Whereas dry mouth, gastritis, and obstipation were more common in the maprotiline-treated group, yawnings and sexual side effects were more common in patients given paroxetine.

In addition to the side-effects of fulfilling patients listed in Table 3, seven patients on maprotiline dropped out because of various side effects: sedation $(n=1)$, a feeling of emotional/cognitive impairment $(n=1)$, headache plus a feeling of emotional/cognitive impairment $(n=1)$, weight gain plus a feeling of emotional/cognitive impairment $(n=1)$, increased anxiety $(n=2)$, and obstipation $(n=1)$. In the paroxetine group, three subjects withdrew from treatment because of side effects: nausea $(n=1)$, anxiety $(n=1)$, and sedation plus a decrease in libido $(n=1)$. In the placebo group, two subjects dropped out because of sedation $(n=2)$.

\section{DISCUSSION}

The study shows that the antidepressant drug paroxetine is an effective treatment for premenstrual complaints. Thus, all the six symptoms that were rated daily 
Table 1. Symptom Rating (median, interquartile range) during the Two Reference Cycles and the Three Treatment Cycles in Patients Administered Paroxetine, Maprotiline, or Placebo

\begin{tabular}{|c|c|c|c|c|c|}
\hline & \multicolumn{2}{|c|}{ Reference Cycle } & \multicolumn{3}{|c|}{ Treatment Cycle } \\
\hline & 1 & 2 & 1 & 2 & 3 \\
\hline \multicolumn{6}{|l|}{ Irritability } \\
\hline Paroxetine & $74.0(42.8)$ & $63.0(42.0)$ & $7.1(17.2)$ & $11.1(21.4)$ & $8.6(15.8)$ \\
\hline Maprotiline & $65.0(43.1)$ & $50.0(44.8)$ & $24.4(36.9)$ & $29.0(29.9)$ & $24.6(37.6)$ \\
\hline Placebo & $65.4(50.0)$ & $62.0(26.0)$ & $29.0(25.7)$ & $36.5(29.5)$ & $33.2(41.7)$ \\
\hline Kruskal-Wallis & $\begin{array}{c}\mathrm{H}=0.4 \\
\mathrm{NS}\end{array}$ & $\begin{array}{c}\mathrm{H}=1.3 \\
\mathrm{NS}\end{array}$ & $\begin{array}{l}H=10.4 \\
p=0.006\end{array}$ & $\begin{array}{l}\mathrm{H}=11.2 \\
p=0.004\end{array}$ & $\begin{array}{l}H=10.3 \\
p=0.006\end{array}$ \\
\hline Paroxetine vs. placebo & - & - & $p=0.002$ & $p=0.001$ & $p=0.004$ \\
\hline Maprolitine vs. placebo & - & - & NS & NS & NS \\
\hline Paroxetine vs. maprolitine & - & - & $p=0.02$ & $p=0.03$ & $p=0.01$ \\
\hline \multicolumn{6}{|l|}{ Depressed mood } \\
\hline Paroxetine & $49.8(51.5)$ & $50.2(47.8)$ & $4.8(13.8)$ & $9.3(20.2)$ & $4.7(18.8)$ \\
\hline Maprotiline & $26.0(37.7)$ & $29.4(46.8)$ & $4.9(12.7)$ & $6.0(10.6)$ & $10.4(20.3)$ \\
\hline Placebo & $42.6(42.7)$ & $54.2(36.9)$ & $28.8(29.9)$ & $21.4(25.5)$ & $23.0(41.9)$ \\
\hline Kruskal-Wallis & $\mathrm{H}=2.7$ & $\mathrm{H}=4.0$ & $H=10.7$ & $H=9.1$ & $\mathrm{H}=8.3$ \\
\hline & NS & NS & $p=0.005$ & $p=0.01$ & $p=0.02$ \\
\hline Paroxetine vs. placebo & - & - & $p=0.004$ & $p=0.03$ & $p=0.005$ \\
\hline Maprotiline vs. placebo & - & - & $p=0.006$ & $p=0.003$ & $p=0.05$ \\
\hline Paroxetine vs. maprotiline & - & - & NS & NS & NS \\
\hline \multicolumn{6}{|l|}{ Anxiety/tension } \\
\hline Paroxetine & $33.1(36.0)$ & $37.5(48.8)$ & $3.3(12.2)$ & $5.2(19.0)$ & $4.5(11.4)$ \\
\hline Maprotiline & $35.6(49.1)$ & $26.2(44.5)$ & $2.2(10.1)$ & $5.5(18.3)$ & $5.8(14.8)$ \\
\hline Placebo & $37.4(63.3)$ & $35.8(49.9)$ & $13.2(30.9)$ & $14.0(17.9)$ & $24.8(30.0)$ \\
\hline Kruskal-Wallis & $\mathrm{H}=1.3$ & $\mathrm{H}=3.2$ & $\mathrm{H}=9.5$ & $\mathrm{H}=2.3$ & $\mathrm{H}=10.3$ \\
\hline & NS & NS & $p=0.009$ & NS & $p=0.006$ \\
\hline Paroxetine vs. placebo & - & - & $p=0.02$ & - & $p=0.004$ \\
\hline Maprotiline vs. placebo & - & - & $p=0.004$ & - & $p=0.01$ \\
\hline Paroxetine vs. maprotiline & - & - & NS & - & NS \\
\hline \multicolumn{6}{|c|}{ Increased appetite/carbohydrate craving } \\
\hline Paroxetine & $49.4(72.0)$ & $61.9(51.8)$ & $14.8(25.6)$ & $13.0(36.8)$ & $14.1(21.4)$ \\
\hline Maprotiline & $41.6(50.6)$ & $38.8(47.5)$ & $18.4(35.1)$ & $14.3(24.4)$ & $20.4(30.1)$ \\
\hline Placebo & $40.1(44.2)$ & $42.6(52.7)$ & $25.8(35.3)$ & $21.0(43.4)$ & $26.6(36.7)$ \\
\hline Kruskal-Wallis & $\mathrm{H}=0.5$ & $\mathrm{H}=4.2$ & $\mathrm{H}=1.2$ & $\mathrm{H}=1.3$ & $\mathrm{H}=4.5$ \\
\hline \multicolumn{6}{|l|}{ Sense of bloating } \\
\hline Paroxetine & $44.5(56.2)$ & $33.0(71.4)$ & $7.6(14.1)$ & $10.4(18.8)$ & $7.1(15.6)$ \\
\hline Maprotiline & $35.2(48.0)$ & $26.3(28.8)$ & $23.0(42.7)$ & $19.4(50.1)$ & $26.6(41.8)$ \\
\hline Placebo & $45.2(40.9)$ & $51.0(49.7)$ & $12.0(37.9)$ & $31.4(44.7)$ & $24.2(52.4)$ \\
\hline Kruskal-Wallis & $\mathrm{H}=0.5$ & $\mathrm{H}=3.9$ & $\mathrm{H}=9.8$ & $\mathrm{H}=8.8$ & $\mathrm{H}=8.5$ \\
\hline & NS & NS & $p=0.007$ & $p=0.01$ & $p=0.01$ \\
\hline Paroxetine vs. placebo & - & - & NS & $p=0.003$ & $p=0.003$ \\
\hline Maprotiline vs. placebo & - & - & NS & NS & NS \\
\hline Paroxetine vs. maprotiline & - & - & $p=0.002$ & $p=0.05$ & NS \\
\hline \multicolumn{6}{|l|}{ Breast tenderness } \\
\hline Paroxetine & $21.7(59.7)$ & $16.7(55.8)$ & $5.1(14.8)$ & $5.2(16.4)$ & $5.3(10.4)$ \\
\hline Maprotiline & $24.6(68.3)$ & $23.2(34.5)$ & $19.8(66.1)$ & $8.0(46.3)$ & $23.0(40.6)$ \\
\hline Placebo & $43.6(43.9)$ & $48.6(53.7)$ & $18.2(34.0)$ & $32.2(39.6)$ & $29.0(42.5)$ \\
\hline \multirow[t]{2}{*}{ Kruskal-Wallis } & $\mathrm{H}=1.9$ & $\mathrm{H}=3.0$ & $\mathrm{H}=6.9$ & $\mathrm{H}=7.2$ & $\mathrm{H}=11.6$ \\
\hline & NS & NS & $p=0.03$ & $p=0.03$ & $p=0.003$ \\
\hline Paroxetine vs. placebo & - & - & $p=0.05$ & $p=0.005$ & $p=0.0005$ \\
\hline Maprotiline vs. placebo & - & - & NS & NS & NS \\
\hline Paroxetine vs. maprotiline & - & - & $p=0.01$ & NS & $p=0.05$ \\
\hline
\end{tabular}

throughout the trial (i.e., irritability, depressed mood, anxiety/tension, increased appetite/craving for carbohydrates, bloating, and breast tenderness) were significantly more reduced in women treated with paroxetine than in those given placebo. Moreover, also as judged by the global self-rating, paroxetine was considerably more effective than was placebo; thus, 19 of
21 fulfilling participants in the paroxetine group, but only 9 of 22 in the placebo group, reported an improvement in premenstrual complaints during treatment. Since paroxetine is a potent serotonin reuptake inhibitor (Caley and Weber 1993; Eriksson and Humble 1990; Turner et al. 1989), the effectiveness of paroxetine in reducing premenstrual complaints is well in line with 
Table 2. Global Change during Drug Treatment as Assessed by the Participants ${ }^{a}$

\begin{tabular}{|c|c|c|c|}
\hline & Placebo & Maprotiline & Paroxetine \\
\hline Enormously improved & 0 & 1 & 6 \\
\hline Much improved & 5 & 7 & 8 \\
\hline Somewhat improved & 4 & 7 & 6 \\
\hline No change & 12 & 4 & 2 \\
\hline Somewhat deteriorated & 1 & 1 & 0 \\
\hline Much deteriorated & 0 & 1 & 0 \\
\hline Enormously deteriorated & 0 & 0 & 0 \\
\hline Kruskal-Wallis $H$-test & $\begin{aligned} H & =13 \\
p & =0.0015\end{aligned}$ & & \\
\hline Mann-Whitney $U$-test & $U=170$ & & \\
\hline Placebo vs. maprotiline & $p=0.14$ & & \\
\hline Mann-Whitney $U$-test & $U=92$ & & \\
\hline Placebo vs. paroxetine & $p=0.0004$ & & \\
\hline Mann-Whitney $U$-test & $U=142$ & & \\
\hline Paroxetin vs. maprotiline & $p=0.03$ & & \\
\hline
\end{tabular}

previous reports indicating that the two potent serotonin reuptake inhibitors clomipramine (Eriksson et al. 1989, 1990; Sundblad et al. 1992, 1993) and fluoxetine (Menkes et al. 1992; Rickels et al. 1990; Stone et al. 1991; Wood et al. 1992) also are effective treatments against PMS. One study showing no superiority of another serotonin reuptake inhibitor, fluvoxamine, over placebo for the treatment of PMS (Veeninga et al. 1990), contrasts with the results obtained with clomipramine, fluoxetine, and paroxetine. However, this trial was small and marred by methodological shortcomings; for example, daily symptom rating was used neither for confirming the diagnosis of PMS before including patients in the study nor for the effect assessment.

The effect of the noradrenaline reuptake inhibitor maprotiline was considerably less impressive than that of paroxetine. For example, the reduction in irritability, bloating, and breast tenderness was no greater in the maprotiline group than in the placebo group; moreover, with respect to all these symptoms, a comparison of the results obtained in the paroxetine- and maprotiline-treated groups, respectively, revealed a significant superiority of the serotonin reuptake inhibitor. Also with respect to global self-rating, patients treated with paroxetine reported a significantly better outcome than those given maprotiline, whereas the ratings of the maprotiline and placebo groups did not differ significantly. The lack of marked effects of maprotiline may seem in conflict with a previous report by Harrison and coworkers (1989) indicating that the noradrenaline reuptake inhibitor nortriptyline is indeed effective in the treatment of PMS. However, the study on nortriptyline was relatively small and did not include a placebo group; moreover, in contrast to maprotiline, nortriptyline does in fact inhibit the reuptake of serotonin (albeit less potently than that of noradrenaline) (Eriksson and Humble 1990). Also, as judged by the data presented in the report by Harrison and cowork- ers, the symptom reduction obtained with nortriptyline was somewhat less impressive than that usually obtained with strong serotonin reuptake inhibitors (e.g., Sunblad et al. 1992).

For both paroxetine and maprotiline, the selection of doses was based on the experience gained from previous trials in depression. Thus, for maprotiline, the recommended dose for the treatment of depression is 75 to $150 \mathrm{mg} /$ day; in the present study, the mean and maximal doses of maprotiline were 119 and $150 \mathrm{mg} /$ day, respectively. Whereas for paroxetine the recommended dose for the treatment of depression is 20 to $50 \mathrm{mg} /$ day, in the present study the mean and maximal doses were 20 and $30 \mathrm{mg} /$ day, respectively. Thus, the relatively weaker effect of maprotiline as compared to paroxetine can hardly be attributed to suboptimal dosage.

The marked superiority of paroxetine over maprotiline in the treatment of premenstrual irritability is particularly notable. Recently, autistic children were shown to respond to treatment with respect to the symptom anger with the strong serotonin reuptake inhibitor clomipramine but not to an antidepressant with a noradrenergic profile (Gordon et al. 1993). Moreover, selective serotonin reuptake inhibitors have been shown to reduce anger attacks, hostility, irritability, and aggression in patients with dementia (Gottfries et al. 1992), depression (Fava et al. 1993), mental retardation (Markowitz 1992), or personality disorder (Cornelius et al. 1991). Thus, pathological irritability, anger, and hostility seem to respond to serotonin reuptake inhibitors regardless of the underlying condition; in contrast, as judged by the present study and by the study on infantile autism (Gordon et al. 1993), noradrenaline reuptake inhibitors seem less effective in this respect. This conclusion is well in line with animal data indicating that serotonin, but not noradrenaline, reduces aggressive behavior (Eriksson and Humble 1990).

It has previously been suggested that the relative 
Table 3. Number of Fulfilling Subjects in Each Group Reporting Side

Effects Lasting for Less or More than 10 Days/Cycle

\begin{tabular}{|c|c|c|c|c|c|c|c|c|c|}
\hline \multirow[b]{2}{*}{ Treatment Cycle: } & \multicolumn{3}{|c|}{$\begin{array}{c}\text { Paroxetine } \\
(n=22)\end{array}$} & \multicolumn{3}{|c|}{$\begin{array}{l}\text { Maprotiline } \\
(n=21)\end{array}$} & \multicolumn{3}{|c|}{$\begin{array}{l}\text { Placebo } \\
(n=22)\end{array}$} \\
\hline & $\mathbf{1}$ & 2 & 3 & 1 & 2 & 3 & 1 & 2 & 3 \\
\hline \multicolumn{10}{|l|}{ Dry mouth } \\
\hline$<10$ days/cycle & 1 & 3 & 2 & 3 & 1 & 5 & 3 & 1 & 1 \\
\hline$\geqslant 10$ days/cycle & 7 & 4 & 2 & 15 & 18 & 12 & 3 & 2 & 1 \\
\hline \multicolumn{10}{|l|}{ Nausea } \\
\hline$<10$ days/cycle & 7 & 4 & 2 & 4 & 1 & 1 & 5 & 3 & 1 \\
\hline$\geqslant 10$ days/cycle & 5 & 1 & 0 & 1 & 0 & 1 & 1 & 0 & 0 \\
\hline \multicolumn{10}{|l|}{ Gastritis } \\
\hline$<10$ days/cycle & 3 & 1 & 1 & 6 & 4 & 5 & 2 & 0 & 0 \\
\hline$\geqslant 10$ days/cycle & 2 & 3 & 3 & 3 & 6 & 4 & 0 & 0 & 0 \\
\hline \multicolumn{10}{|l|}{ Obstipation } \\
\hline$<10$ days/cycle & 1 & 1 & 4 & 3 & 3 & 5 & 5 & 1 & 0 \\
\hline$\geqslant 10$ days/cycle & 4 & 4 & 3 & 11 & 12 & 10 & 1 & 2 & 2 \\
\hline \multicolumn{10}{|l|}{ Diarrhea } \\
\hline$<10$ days/cycle & 1 & 2 & 0 & 0 & 0 & 0 & 1 & 1 & 0 \\
\hline$\geqslant 10$ days/cycle & 0 & 2 & 0 & 0 & 0 & 0 & 2 & 1 & 0 \\
\hline \multicolumn{10}{|l|}{ Sleep disturbance } \\
\hline$<10$ days/cycle & 1 & 1 & 0 & 1 & 0 & 2 & 1 & 0 & 1 \\
\hline$\geqslant 10$ days/cycle & 3 & 2 & 2 & 1 & 1 & 0 & 1 & 1 & 2 \\
\hline \multicolumn{10}{|l|}{ Sedation } \\
\hline$<10$ days/cycle & 2 & 2 & 2 & 3 & 4 & 5 & 1 & 1 & 1 \\
\hline$\geqslant 10$ days/cycle & 12 & 9 & 6 & 14 & 10 & 7 & 7 & 5 & 3 \\
\hline \multicolumn{10}{|l|}{ Yawnings } \\
\hline$<10$ days/cycle & 1 & 2 & 2 & 2 & 1 & 2 & 1 & 1 & 0 \\
\hline$\geqslant 10$ days/cycle & 7 & 4 & 1 & 2 & 0 & 0 & 1 & 0 & 0 \\
\hline \multicolumn{10}{|l|}{ Palpitations } \\
\hline$<10$ days/cycle & 4 & 2 & 0 & 5 & 2 & 2 & 2 & 0 & 1 \\
\hline$\geqslant 10$ days/cycle & 1 & 0 & 2 & 1 & 1 & 1 & 1 & 1 & 1 \\
\hline \multicolumn{10}{|l|}{ Blurred vision } \\
\hline$<10$ days/cycle & 2 & 3 & 1 & 3 & 2 & 4 & 1 & 0 & 0 \\
\hline$\geqslant 10$ days/cycle & 4 & 1 & 2 & 4 & 5 & 2 & 3 & 4 & 4 \\
\hline \multicolumn{10}{|l|}{ Headache } \\
\hline$<10$ days/cycle & 4 & 4 & 1 & 3 & 2 & 2 & 1 & 1 & 5 \\
\hline$\geqslant 10$ days/cycle & 3 & 2 & 3 & 1 & 1 & 1 & 5 & 1 & 5 \\
\hline \multicolumn{10}{|l|}{ Tremor } \\
\hline$<10$ days/cycle & 3 & 1 & 1 & 5 & 1 & 2 & 0 & 0 & 0 \\
\hline$\geqslant 10$ days/cycle & 0 & 0 & 0 & 2 & 2 & 2 & 1 & 0 & 0 \\
\hline Paresthesiae, numbness & & & & & & & & & \\
\hline$<10$ days/cycle & 3 & 1 & 0 & 2 & 1 & 0 & 0 & 1 & 0 \\
\hline$\geqslant 10$ days/cycle & 1 & 2 & 2 & 1 & 0 & 0 & 0 & 0 & 0 \\
\hline Vertigo & & & & & & & & & \\
\hline$<10$ days/cycle & 6 & 3 & 1 & 6 & 4 & 4 & 4 & 1 & 2 \\
\hline$\geqslant 10$ days/cycle & 1 & 0 & 1 & 4 & 2 & 2 & 1 & 0 & 0 \\
\hline Sexual side effects & & & & & & & & & \\
\hline$<10$ days/cycle & 3 & 1 & 1 & 1 & 2 & 1 & 0 & 1 & 0 \\
\hline$\geqslant 10$ days/cycle & 4 & 4 & 6 & 2 & 1 & 1 & 0 & 0 & 1 \\
\hline Anxiety & & & & & & & & & \\
\hline$<10$ days/cycle & 2 & 0 & 0 & 1 & 1 & 2 & 1 & 1 & 0 \\
\hline$\geqslant 10$ days/cycle & 0 & 1 & 0 & 0 & 1 & 0 & 1 & 0 & 0 \\
\hline Sweatings & & & & & & & & & \\
\hline$<10$ days/cycle & 2 & 2 & 3 & 0 & 0 & 2 & 0 & 0 & 0 \\
\hline$\geqslant 10$ days/cycle & 4 & 6 & 3 & 5 & 4 & 4 & 2 & 1 & 0 \\
\hline Skin rash & & & & & & & & & \\
\hline$<10$ days/cycle & 1 & 1 & 0 & 1 & 0 & 0 & 1 & 1 & 0 \\
\hline$\geqslant 10$ days $/$ cycle & 1 & 0 & 0 & 1 & 1 & 1 & 0 & 0 & 0 \\
\hline
\end{tabular}

efficacies of serotonin and noradrenaline reuptake inhibitors, respectively, are more related to the symptom that is to be reduced than to the underlying condition; thus, whereas both types of reuptake inhibitors are equally effective in reducing depressed mood (Bouchard et al. 1987), selective serotonin reuptake inhibitors may be superior in reducing symptoms such as poor impulse control and anxiety (Eriksson and Hum- 
ble 1990; van Praag et al. 1987). The present results lend some support for this concept; thus, whereas premenstrual irritability was more effectively reduced by paroxetine than by maprotiline, with respect to the reduction in depressed mood, the difference between the maprotiline- and paroxetine-treated groups did not reach statistical significance. However, the interpretation of the effect of maprotiline on depressed mood in the present study was marred by the difference between groups apparent for this particular symptom already before treatment (largely due to the fact that several of the participants with severe premenstrual sadness in the maprotiline group dropped out early during treatment). Thus, although the rating of depressed mood during treatment cycle 3 was significantly lower in the maprotiline group than in the placebo group, the difference between the maprotiline and placebo groups with respect to the relative reduction in depressed mood (expressed as percent of baseline rating) did not reach statistical significance $(p=.1)$. Whereas an effect of maprotiline on premenstrual sadness in women with PMS hence cannot be excluded, no definite support for such an effect was obtained.

The symptom that appeared most susceptible to treatment with maprotiline was premenstrual anxiety/tension; thus, albeit the difference between the maprotiline and the placebo groups with respect to the reduction of the anxiety/tension rating did not reach statistical significance $(p=.052)$ either, the anxietyreducing effect of maprotiline was of about the same magnitude as that of paroxetine. This finding is somewhat unexpected given the marked superiority of serotonin reuptake inhibitors over noradrenaline reuptake inhibitors in other conditions characterized by anxiety, such as panic disorder (Eriksson and Humble 1990). However, when interpreting the reduction in anxiety rating observed in the maprotiline group, it should be taken into consideration that maprotiline is not only a potent noradrenaline reuptake inhibitor but also an effective histamine $\mathrm{H}_{1}$-receptor antagonist (Kanba et al. 1984). Hence, it cannot be excluded that the anxiety reduction obtained by maprotiline is related to the antihistaminergic sedation induced by the drug rather than to the inhibition of noradrenaline reuptake.

The impressive paroxetine-induced reduction in the somatic symptoms bloating and breast tenderness is noteworthy. Similarly, treatment with clomipramine (Sundblad et al. 1992) and fluoxetine (Wood et al. 1992) each day of the menstrual cycle has been shown to reduce not only the mental symptoms of PMS but also various somatic complaints. In contrast, intermittent administration of clomipramine during the luteal phase only, although effectively reducing premenstrual irritability and depressed mood within a few days after the onset of treatment, did not reduce bloating and breast tenderness (Sundblad et al. 1993). Thus, it may be suggested that when using serotonin reuptake inhibitors for the treatment of PMS, the lag phase between onset of treatment and onset of effect is shorter for mental symptoms such as irritability and depressed mood than for somatic complaints such as bloating and breast tenderness. The mechanism of action for the somewhat unexpected effect of serotonin reuptake inhibitors on somatic symptoms remains to be elucidated.

The side effects of paroxetine were generally weak and tolerable, and most participants in the paroxetine group elected to continue treatment after the end of the trial. As would be expected from a strong serotonin reuptake inhibitor, sexual side effects, yawnings, and, during the first treatment cycle, nausea, appeared to be the most cumbersome unwanted effects (Caley and Weber 1993; Turner et al. 1989). In the maprotiline group, dry mouth, obstipation, and sedation, were the most frequent side effects (Pinder et al. 1977).

To conclude, the main finding of the present study is that a selective serotonin reuptake inhibitor, paroxetine, is clearly superior to a selective noradrenaline reuptake inhibitor, maprotiline, in the treatment of PMS. A superiority of serotonin reuptake inhibitors over noradrenaline reuptake inhibitors has previously been reported for various conditions characterized by impaired impulse control (obsessive compulsive disorder, onychophagia, trichotillomania) (Leonard et al. 1991; Swedo et al. 1989; Thorén et al. 1980); or anxiety (panic disorder) (Den Boer and Westenberg 1988; Modigh et al. 1992); in contrast, in the treatment of depression, selective serotonin reuptake inhibitors are not superior to selective, or preferential, noradrenaline reuptake inhibitors (Bouchard et al. 1987; see also Eriksson and Humble 1990).

A conclusion of practical importance that can be drawn from the present study is that paroxetine seems to be an effective and well-tolerated alternative for the treatment of the mental as well as the somatic manifestations of severe PMS.

\section{ACKNOWLEDGMENTS}

This study was part of a PMS research program supported by grants from the Swedish Medical Research Council (04752 and 08668), Novo Nordisk Pharma AB, Malmö, Sweden, and Ciba AB, Göteborg, Sweden. Margareta Lundgren and Norunn Persson are gratefully acknowledged for excellent technical assistance.

\section{REFERENCES}

American Psychiatric Association (1985): Diagnostic and Statistical Manual of Mental Disorders, ed 3, rev, Washington, DC: APA Press

Andersch B, Wendestam C, Hahn L, Öhman R (1986): Premenstrual complaints. I. Prevalence of premenstrual symptoms in a Swedish urban population. J Psychosom Obstet Gynaecol 5:39-49 
Bouchard JM, Delaunay J, Delisle JP, Grasset N, Mermberg PF, Molczadzki M, Pagot R, Richou H, Robert G, Ropert $R$ (1987): Citalopram versus maprotiline: A controlled, clinical multicentre trial in depressed patients. Acta Psychiatr Scand 76:583-592

Caley CF, Weber SS (1993): Paroxetine: A selective serotonin reuptake inhibiting antidepressant. Ann Pharmacother 27:1212-1222

Chihal HJ (1987): Indications for drug therapy in premenstrual syndrome patients. Journal of Reprod Med 32:449-452

Cornelius JR, Soloff PH, Perel JM, Ulrich RF (1991): A preliminary trial of fluoxetine in refractory borderline patients. J Clin Psychopharmacol 11:116-120

Den Boer JA, Westenberg HG (1988): Effect of a serotonin and noradrenaline uptake inhibitor in panic disorder: A double-blind comparative study with fluvoxamine and maprotiline. Int Clin Psychopharmacol 3:59-74

Eriksson E, Humble M (1990): Serotonin in psychiatric pathophysiology. A review of data from experimental and clinical research. In Pohl R, Gershon S (eds), The Biological Basis of Psychiatric Treatment, Basel: Karger, pp 66-119

Eriksson E, Andersch B, Andersson K, Lisjö P, Modigh K (1989): Clomipramine in the premenstrual syndrome: A pilot study. In Stefanis SN, Soldatos CR, Rabavilas AD (eds), Psychiatry Today, VIII World Congress of Psychiatry, Excerpta Medica International Congress Series 899, Amsterdam: Elsevier, p 532

Eriksson E, Lisjö P, Sundblad C, Andersson K, Andersch B, Modigh K (1990): Clomipramine in the premenstrual syndrome. Acta Psychiatr Scand 81:87-88

Fava M, Rosenbaum JF, Pava JA, McCarthy MK, Steingard RJ, Bouffides E (1993): Anger attacks in unipolar depression, Part 1: Clinical correlates and response to fluoxetine treatment. Am J Psychiatry 150:1158-1163

Frank RT (1931): The hormonal causes of premenstrual tension. Arch Neurol Psychiatry 26:1053-1057

Gordon CT, State RC, Nelson JE, Hamburger SD, Rapoport JL (1993): A double-blind comparison of clomipramine, desipramine, and placebo in the treatment of autistic disorder. Arch Gen Psychiatry 50:441-447

Gottfries CG, Karlsson I, Nyth A-L (1992): Treatment of depression in elderly patients with and without dementia disorders. Int Clin Psychopharmacol 6:55-64

Graze KK, Nee J, Endicott J (1990): Premenstrual depression predicts future major depressive disorder. Acta Psychiatr Scand 81:201-205

Halbreich U, Endicott J, Schacht S, Nee J (1982): The diversity of premenstrual changes as reflected in the Premenstrual Assessment Form. Acta Psychiatr Scand 65:46-65

Hallman J (1986): The premenstrual syndrome-An equivalent of depression? Acta Psychiatr Scand 73:403-411

Harrison WM, Endicott J, Nee J (1989): Treatment of premenstrual depression with nortriptyline: A pilot study. J Clin Psychiatry 50:136-139

Kanba S, Rickelson E (1984): Histamine H1 receptors in human brain labelled with (3H)doxepine. Brain Res 304:1-7

Leonard HL, Lenane MC, Swedo SE, Rettew DC, Rapoport JL (1991): A double-blind comparison of clomipramine and desipramine treatment of severe onychophagia (nail biting). Arch Gen Psychiatry 48:821-827
Markowitz PI (1992): Effect of fluoxetine on self-injurious behavior in the developmentally disabled: A preliminary study. J Clin Psychopharmacol 12:27-31

Menkes DB, Taghavi E, Mason PA, Spears GFS, Howard RC (1992): Fluoxetine treatment of severe premenstrual syndrome. BMJ 305:346-347

Merikangas KR, Foeldenyi M, Angst J (1993): The Zurich Study. XIX. Patterns of menstrual disturbances in the community: Results of the Zurich Cohort Study. Eur Arch Psychiatry Clin Neurosci 243:23-32

Modigh K, Westberg P, Eriksson E (1992): Superiority of clomipramine over imipramine in the treatment of panic disorder: A placebo-controlled trial. J Clin Psychopharmacol 12:251-261

Pearlstein TB, Frank E, Rivera-Tovar A, Thoft JS, Jacobs E, Mieczkowski TA (1990): Prevalence of Axis I and Axis II disorders in women with late luteal phase dysphoric disorder. J Affect Disord 20:129-134

Pinder RM, Brogden RN, Speight TM, Avery GS (1977): Maprotiline: A review of its pharmacological properties and therapeutic efficacy in mental depressive states. Drugs 13:321-352

Reid RL (1985): Premenstrual syndrome. Curr Probl Obstet Gynecol Fertil 8:7-9

Rickels K, Freedman EW, Sondheimer S, Albert J (1990): Fluoxetine in the treatment of premenstrual syndrome. Curr Ther Res 48:161-166

Stone AB, Pearlstein TB, Brown WA (1991): Fluoxetine in the treatment of late luteal phase dysphoric disorder. J Clin Psychiatry 52:290-293

Sundblad C, Hedberg MA, Eriksson E (1993): Clomipramine administered during the luteal phase reduces the symptoms of premenstrual syndrome: A placebo-controlled trial. Neuropsychopharmacology 9:133-145

Sundblad C, Andersch B, Modigh K, Eriksson E (1992): Clomipramine effectively reduces premenstrual irritability and dysphoria: A placebo-controlled trial. Acta Psychiatr Scand 85:39-47

Swedo SE, Leonard HL, Rapoport JL, Lenane MC, Goldberger EL, Cheslow DL (1989): A double-blind comparison of clomipramine and desipramine in the treatment of trichotillomania (hair pulling). N Engl J Med 321:497-501

Thorén P, Åsberg M, Cronholm B, Jornestedt L, Träskman L (1980): Clomipramine treatment of obsessive-compulsive disorder. I. A controlled clinical trial. Arch Gen Psychiatry 37:1281-1285

Turner P, Wallinder J, Dunbar GC (eds) (1989): The antidepressant paroxetine: A specific serotonin reuptake inhibitor. Acta Psychiatr Scand 80 (suppl).

van Praag HM, Kahn R, Asnis GM, Lemus CZ, Brown SL (1987): Therapeutic indications for serotonin-potentiating compounds: An hypothesis. Biol Psychiatry 22:205-212

Veeninga AT, Westenberg HGM, Weusten JTN (1990): Fluvoxamine in the treatment of menstrually related mood disorders. Psychopharmacology 102:414-416

Wood SH, Mortola JF, Chan YF, Moossazadeh F, Yen SS (1992): Treatment of premenstrual syndrome with fluoxetine: A double-blind, placebo-controlled, crossover study. Obstet Gynecol 80:339-344 